\title{
Corporate social responsibility vs. financial interests: the case of responsible gambling programs
}

\author{
Ingo Fiedler ${ }^{1,2}$ (D) Sylvia Kairouz ${ }^{1} \cdot$ Jennifer Reynolds ${ }^{1}$
}

Received: 28 May 2019 / Accepted: 23 January 2020 / Published online: 6 February 2020

(C) The Author(s) 2020

\begin{abstract}
Aim Corporate social responsibility (CSR) is supposed to play an important part in public health. Critics argue that opposing financial interests can prevent companies from implementing effective CSR programs. We shed light on this discussion by analyzing CSR programs of gambling operators.

Subjects and methods Two data sets are used: (1) seven responsible gambling (RG) programs of German slot machine hall operators and (2) a survey carried out among 512 problem gamblers in treatment who play primarily in slot machines halls.

Results Results show that the RG programs list mostly mandatory measures with one major exception: to approach possible problem gamblers with the intention to help them. However, operators' staff approach only $1 \%$ of problem gamblers.

Conclusion We argue that the observed ineffective implementation of voluntary CSR measures is grounded in the strong financial incentive of operators to serve precisely the group they should stop from playing: problem gamblers. We conclude that financial interests reduce the effectiveness of CSR.
\end{abstract}

Keywords Public health $\cdot$ Responsible gambling $\cdot$ Conflict of interests $\cdot$ Demerit goods

\section{Introduction}

Voluntary self-regulatory measures often come under criticism for only being implemented to deter stronger mandatory regulations. In this article, we examine corporate social responsibility in an area that has been a controversial business for centuries and today is a concern for public health: gambling (Leung and Snell 2017). While gambling yields pleasure to some consumers, it can harm pathological gamblers and their environment. Often referred to as a demerit good requiring treatment different from other goods, gambling regulators

Ingo Fiedler

ingo.fiedler@uni-hamburg.de

Sylvia Kairouz

sylvia.kairouz@concordia.ca

Jennifer Reynolds

jenniferann.reynolds@concordia.ca

1 Department of Sociology and Anthropology, Research Chair on Gambling, Concordia University Montreal, 2070 Mackay Street, 3rd floor, Montreal, QC H3G 2J1, Canada

2 Faculty of Business, Economics \& Social Sciences, Universität Hamburg, Von-Melle-Park 5, 20146 Hamburg, Germany regularly demand strong corporate social responsibility (CSR) from operators.

Alcohol experts have voiced similar concerns about the self-regulatory measures and responsible drinking practices of the alcohol industry (Savell et al. 2016). Because of the alcohol industry's profitability objectives, some studies argue that the alcohol industry is purposively producing responsible drinking campaigns for marketing purposes (Barry and Goodson 2010). These not only fail to achieve significant behavioral change among drinkers but can also be considered harmful, reinforcing current drinking behaviors (Pettigrew et al. 2016).

In 2012, a similar critique was raised in Germany when it became mandatory by law for private operators of slot machines to have a responsible gambling ( $\mathrm{RG}$ ) program but the operators were given broad scope in drafting these programs. While some measures within these programs were mandatory, the idea was that operators would also implement voluntary measures. Critics raised the suspicion that such programs not only lack effective voluntary measures, but even the mandatory ones might not be fully complied because of the lack of sanctions. Following this critique, the concept of responsible gambling programs is an ineffective player protection measure that not only produces costs but might even hinder the implementation of more effective measures. 
In this article, we investigate whether this critique is correct by (1) analyzing seven responsible gambling programs to determine if they contain voluntary measures and whether these measures can potentially yield effective player protection and (2) surveying 512 gamblers in treatment, who mainly gamble at slot machine halls, to discern whether the measures within the programs are put into practice.

\section{Literature Review and Hypotheses}

The primary goal of a private business, including gambling operators, is to maximize profits. Operators pursue this goal under the requirements of regulatory constraints. However, the behavior of companies often still has consequences that are external to its profit function and negatively affect the public, including health effects. In an attempt to deal with these consequences and achieve a balance among the economic, environmental, and social aspects, as well as imperatives, firms engage in corporate social responsibility (CSR) efforts (Swathi 2018). CSR has been defined as "a concept whereby companies integrate social and environmental concerns in the business operation and their interactions with their stakeholders on a voluntary basis" (The Commission of the European Communities 2001, p. 6).

Cai et al. (2012) posed the question: Can firms in controversial industries be socially responsible while producing products harmful to a human being, society, or environment? Examining the CSR engagement of firms involved in supplying goods with negative health effects (e.g., tobacco, gambling, alcohol), the study sought to investigate the relation between a firm's choice of CSR activities and its market value, finding that after controlling for various firm characteristics, CSR engagement was positively associated with firm value, consistent with a value-enhancement hypothesis. In essence, this shows that businesses in controversial industries utilizing CSR as a means to improve transparency, strategies, and philanthropy also enhance firm value (Cai et al. 2012). This finding suggests that businesses have an intrinsic interest in engaging in CSR. But is that also true when CSR opposes financial interests, for example, when a firm is selling addictive goods and is supposed to block access to some of their customers?

\section{CSR in the alcohol market}

The discussion on CSR in markets for demerit goods with negative effects on adult public health focuses mostly on alcohol. Under the general framework of corporate social responsibility, the alcohol industry has increased 'responsible drinking' prevention activities. Most of these have often been described as instrumental to the industry's economic interest (Babor and Robaina 2013) and designed to maximize the long-term profits (Garriga and Melé 2004). The very term "responsible drinking" has been challenged by researchers, who consider such messaging to be intentionally ambiguous and potentially part of strategies to protect the industry's interests (Hessari and Petticrew 2017).

A content analysis study concluded that these 'responsible drinking' campaigns strategically enable the industry to confuse the presentation of health information and sometimes undermine official government instructions on alcohol harm (Jones et al. 2017). It has been shown that viewers unequivocally interpret government-developed campaigns as warnings against the harmful consumption of alcohol while industry messages are associated with a range of interpretations, sometimes understood as an encouragement to consume more alcohol (Jones et al. 2017). Thus, these initiatives instead serve to brighten the image of the industry while being ineffective in moderating consumption (Jones et al. 2017).

Studies also indicate that cost-effective interventions are those, often neglected, that are focused on total populations, controlling availability, affordability, marketing of alcohol, and drinking and driving (Casswell and Thamarangsi 2009; Room et al. 2005). By contrast, campaigns targeting individual behavioral change have not yet been proven to be significantly effective when it comes to harm reduction. On the contrary, they can sometimes prove to be counterproductive as most ads tend to focus on short-term harms while the most difficult alcohol-related problems are associated with longterm usage, emphasizing individual risk management and responsibilization (Dunstone et al. 2017) again.

\section{Responsible gambling, CSR, and public health}

By the late 1990s, gambling expansion was established as a public health issue (Korn and Shaffer 1999), garnering attention to address concerns regarding problem gambling and reducing associated harms to players and the community. In turn, governments and organizations providing gambling services, particularly electronic gambling machines, felt pressure to demonstrate their commitment to CSR and adopt responsible gambling (RG) policies (Hing 2002; Hing 2010; Reith 2008).

Calls to understand CSR in dangerous consumption industries, such as pharmaceuticals, tobacco, alcohol, and gambling, have been issued (Devinney 2009; Leung and Snell 2017). As reviewed by Leung and Snell (2017), CSR in the gambling industry has received scholarly attention with studies investigating the impact of CSR on financial performance, consumers' perceptions of gambling, and perceptions of RG by casino employees. However, whether these RG programs achieved the positive effect on player protection and public health that they were designed for was not sufficiently tested.

Since 2004, the construction of RG has primarily been associated with a series of position papers referred to as the Reno Model I-V (Blaszczynski et al. 2004; Blaszczynski et al. 
2008; Blaszczynski et al. 2011; Collins et al. 2015; Ladouceur et al. 2017). Responsible gambling, as defined by the Reno model authors Blaszczynski et al. (2004), comprises policies and practices designed to prevent and reduce potential harms associated with gambling, incorporating a diverse range of interventions designed to promote consumer protection, community/consumer awareness and education, and access to efficacious treatment. In this light, gaming corporations and associated governmental bodies rest upon an individual's right to informed freedom of choice.

To classify RG programs as supporting public health, there is an expectation that these codes will exceed the mandatory measures demanded by law and include additional voluntary measures. Mandatory measures for gambling halls in Germany are, most notably, the legal age of 18 years and the prohibition of smoking and alcohol in slot machine halls (but not at machines in bars). The German gambling treaty of 2012 states that gambling operators are obliged to "encourage gamblers to play responsibly and prevent the emergence of gambling addiction" ( $\$ 6$ gambling treaty). This rather general rule is made more concrete in the appendix of the treaty that defines these mandatory measures for RG programs: (1) appointment of a director for the development of the RG program, (2) training of staff to detect potential problem gambling behavior; (3) regular documentation and reporting on the effects of the RG programs, (4) provision of information to players about, for example, chances of winnings, a self-test of gambling problems, and a hotline for gambling problems; (5) a prohibition against sharing revenues with senior staff; (6) a prohibition against any of the staff participating in gambling.

The combined requirements to train staff and to encourage players to gamble responsibly could be understood as operators having the duty to proactively approach potential problem gamblers with the intention to help them by, for example, referring them to treatment. While such an approach is a promising prevention effort, we do not see it as a mandatory rule but rather as a voluntary measure for two reasons: (1) neither the gambling treaty nor its appendix explicitly state that the encouragement to play responsibly has to involve a proactive personal approach by staff members or that it should involve a referral to treatment; (2) if mandatory, such an obligation would induce a liability of the operators to compensate customers for damages to a pathological gambler in case of non-compliance - a liability that has not been recognized by courts. Still, we acknowledge that an interpretation of approaching potential problem gamblers as a mandatory measure is tenable. In that case a violation against the rule would be more severe, since it is mandatory and not voluntary.

\section{Revenue sharing with problem gamblers}

Spending for gambling is highly concentrated in a small group of high-intensity gamblers (Fiedler et al. 2019). For example, $80 \%$ of revenue from fixed-odds sports betting is generated by $5.7 \%$ of high-intensity gamblers (Tom et al. 2014). In poker, revenue is yet more concentrated: $1 \%$ of the gamblers account for $60 \%$ of operators' revenue, $5 \%$ account for $83 \%$, and the top $10 \%$ of players deliver $91 \%$ of the operators' income (Fiedler 2012, p. 17). The dose-response relationship suggests that gambling problems and the amount of money spent are positively correlated (Currie et al. 2009; Brosowski et al. 2015) and hence that problem gamblers account for a relatively large proportion of spending.

A number of studies provide evidence on the diverging spending habits of recreational gamblers and problem gamblers (Smith and Wynne 2002; Wiebe et al. 2006; Volberg and Bernhard 2006; Fiedler et al. 2019). The gambling report by the Australian Productivity Commission explores asymmetries in gambling expenses in even greater depth and concludes that addicted slot machine gamblers play more often, play in longer sessions, and wager more per time unit (Productivity Commission 2010). The share of gambling revenue derived from specific game forms is not well documented but the existing literature suggests that slot machines have a rather large share. Williams and Wood (2007) assess a share of $61 \%-62 \%$ for slot machines in Ontario. Fiedler et al. (2019) observe $40.2 \%$ for slot machines in France and $76.3 \%$ in Québec. Smith and Wynne (2002) even find a share of $91.3 \%$ for slot machines in Alberta. For Germany, Fiedler (2016, p. 360) estimates the share of gambling hall revenues from pathological gamblers to lie between $67 \%$ and $77 \%$. These findings show that slot machine operators have a strong financial incentive to serve problem gamblers. If they would engage in perfect prevention and exclude all problem gamblers as clients, they would lose a very large share of their revenues.

\section{Hypotheses}

In this article, we operationalize CSR as introducing effective RG measures that either prevent problem gambling or reduce existing harms to problem gamblers. Against the backdrop of the concentration of revenues in problem gamblers and financial incentives of slot machine operators, we hypothesize that voluntary measures of RG in RG programs are limited in number and extent of implementation. We operationalize this in two working hypotheses:

Hypothesis $\mathbf{H}_{\mathbf{A}}$ : On paper, responsible gambling programs contain mainly mandatory measures whereas additional effective voluntary measures are absent.

Hypothesis $\mathbf{H}_{B}$ : In practice, voluntary measures of responsible gambling programs are not sufficiently implemented. 


\section{Methods}

Our study contains two data sets: (1) the contents of responsible gambling programs of seven German slot machine operators and (2) survey data of gamblers in treatment. The first data set was analyzed in the form of a manual content analysis to test $\mathrm{H}_{\mathrm{A}}$, and the second data set was used to test $\mathrm{H}_{\mathrm{B}}$ with SPSS and descriptive statistics.

\section{Data set 1: Responsible gambling programs}

The first data set consists of seven RG programs of the following companies:
1. Löwen Play
2. Crown Automaten
3. Schmidt Gruppe
4. AMA Arbeitsausschuss Münzautomaten
5. MoHR Spielhallen
6. Rösner Automaten $\mathrm{GmbH}$
7. Vulkan Stern

These were all RG programs of slot machine hall operators available at the time of the analysis. Each of these documents was systematically analyzed in detail to qualitatively identify RG measures aimed at protecting gamblers. We classified each measure as either mandatory or voluntary based on current German legislation. This data set was used to test hypothesis $\mathrm{H}_{\mathrm{A}}$ by investigating whether the prevention measures outlined above are present in the respective RG programs.

\section{Data set 2: Survey of gamblers in treatment}

In 2014, a survey was conducted with 705 gamblers in treatment centers across Germany. The target group was problem gamblers who are targeted by the measures of RG programs, particularly the voluntary measure to be approached by staff and referred to treatment. To reach this sample, a collaboration with the German treatment network was established that distributed the questionnaire to treatment centers in 15 of the 16 German federal states. Each respondent was approached by the treatment center and gave their consent to answer the questionnaire and participate in the study. The final sample consisted of 655 gamblers who had actively participated in gambling over the past 12 months and thus after the new law requiring $R G$ programs was in effect. This left 50 abstinent gamblers excluded from the analysis. The data set was then further reduced to 512 gamblers who indicated that they primarily played in slot machine halls. Gamblers using the other gambling forms were too few to derive separate statistically significant results for $R G$ programs of operators of other gambling forms.
Each respondent answered the $\mathrm{CCCC}$ test, a brief screen for problem gambling, adapted from the Cage alcoholism diagnostic screen (Mayfield et al. 1974). A preliminary diagnosis of pathological gambling is determined if participants positively answer two or more questions (Petry 2003). Of the 512 primarily slot machine gamblers, $91.4 \%$ scored positively on two items or more. This data set was used to test hypothesis $\mathrm{H}_{\mathrm{B}}$.

\section{Results}

\section{Analysis of responsible gambling programs}

To test Hypothesis $\mathrm{H}_{\mathrm{A}}$, we analyzed the content of all seven $\mathrm{RG}$ programs regarding the player protection measures mentioned, distinguishing between voluntary and mandatory measures. All RG programs contain the mandatory RG measures. Some voluntary measures were also found in more than one program and claimed to be "continually advancing the RG program" (mentioned six times), "supporting initiatives to protect players" (5 out of 7), "appointing a commissioner for prevention efforts" (4 out of 7), "training staff without customer contact" ( 2 out of 7 ), or "establishing a culture of player protection" ( 2 out of 7). All these measures are indirect in the sense that they do not have an effect on player protection per se but only through additional actions that might be induced by the measures, for example, a commissioner developing a new prevention measure. Only two voluntary direct measures were found, each in only one program. One relates to the enforcement of the program itself by "regular controls and mystery shopping." Another program mentioned denying entrance to a slot machine hall for people under the age of 21. Further voluntary measures were not found, including measures that could have been expected, for example, a (self-)limitation system for players, a (self-)exclusion system for players, or a reduction of the maximum playing speed. While we found mentions of banning alcohol, it was only in reference to slot machine halls where alcohol is prohibited by law, but not for bars, where it could have been an effective voluntary measure; it could thus not be classified as a voluntary measure.

Most importantly, in all seven programs, we found the mandatory measure to train staff and a further measure to approach potential problem gamblers (7 out of 7) and to refer them to the help system (6 out of 7). We thus have mixed results for Hypothesis $\mathrm{H}_{\mathrm{A}}$ : Only few voluntary measures were found in the RG programs that could have a direct effect on player protection, while some player protection measures that could have been expected were missing. However, all RG programs contain the potentially very useful measures of approaching problem gamblers and referring them to treatment. 
Whether these measures are effectively implemented is tested in another data set.

\section{Survey of gamblers in treatment}

To test Hypothesis $\mathrm{H}_{\mathrm{B}}$, gamblers in treatment who prefer to gamble at slot machines in gambling halls were asked in a survey (1) whether staff noticed when they had significant losses (interpreted as an indicator of gambling problems) and (2) whether they had the impression that staff noticed their gambling problems. The critical questions were about the reaction of staff members when seeing significant losses or gambling problems: did they approach gamblers to discourage gambling as the RG programs intend them to do? Or instead, were gamblers encouraged to continue gambling?

Of the 512 slot machine gamblers, $43.6 \%(n=223)$ felt that their significant gambling losses were noticed by the staff (see Fig. 1), while $41.7 \%$ did not perceive that staff were aware of their losses, and $14.1 \%$ reported being unsure. Furthermore, of the gamblers who felt that staff took notice of their large losses, $43.5 \%(n=97)$ reported not being approached, i.e., staff neither encouraged nor discouraged them from continuing to gamble. Only $3.1 \%(n=7)$ of the individuals approached were strongly discouraged from continuing to gamble and 9.9\% $(n=22)$ of the individuals were lightly discouraged. Most notably, $43.4 \%$ $(n=97)$ of gamblers reported being either lightly or strongly encouraged to continue playing.

With respect to gambling problems noticed by staff (see Fig. 2), survey results indicate that $36.9 \%(n=189)$ of slot machine gamblers felt that staff members noticed their gambling problems. However, staff approached only $1 \%(n=5)$ of problem gamblers and referred them to the help systems (e.g., treatment, hotline) as outlined as a voluntary measure in the responsible gambling programs. This confirms hypothesis $\mathrm{H}_{B}$ that voluntary responsible gambling measures are not sufficiently implemented.

\section{Discussion}

Social benefits of gambling arise through the pleasure of recreational gambling, revenue to operators, and the creation of jobs and taxes (Fiedler 2016). Conversely, gambling creates social costs in the form of problem gamblers and the harm they impose upon themselves and their environment, as well as the overall society, through reduced quality of life, reduced income and productivity, treatment costs, and follow-up costs of delinquency (Fiedler 2016). Effective RG efforts reduce problem gambling and the associated costs and can thus be seen as CSR that benefits public health.

We argue that a gambling operator who is concerned about public health should implement an RG program that exceeds the mandatory measures and includes voluntary measures that promise to have a substantial effect on reducing problem gambling and its consequences. The content analysis of the RG programs showed mixed results. Most programs list mandatory measures while the mentioned voluntary measures are not explicit. There are only indirect measures such as appointing a commissioner for the program while the expected measures such as (self-)limitation or (self-)exclusion systems are missing. This non-finding can be interpreted as either a lack of knowledge on behalf of operators about these measures or a lack of interest in integrating them.

The one major exception was the voluntary measure to train staff to detect and refer problem gamblers to help services and treatment. However, while this measure was mentioned in all RG programs, data from a survey among 512 gamblers in treatment centers who had primarily played slot
Fig. 1 Staff reaction to large gambling losses. Out of 512 gamblers in treatment, 223 had the impression that staff members noticed when they had large gambling losses. Among them, 29 gamblers felt discouraged and 97 gamblers encouraged to continue gambling

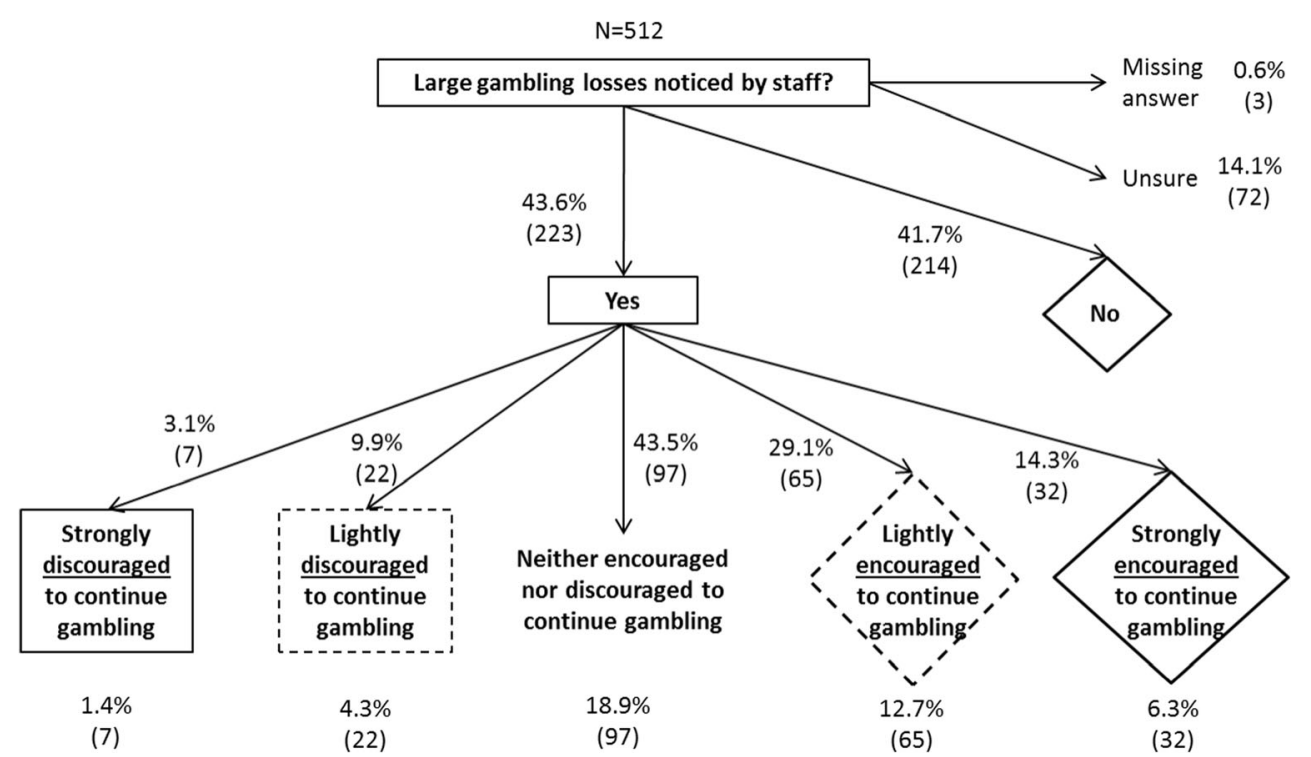


Fig. 2 Staff reaction to gambling problems. Of 512 gamblers in treatment, 189 had the impression that staff members noticed their gambling problems. Eight gamblers were actually approached by staff and six gamblers actually helped

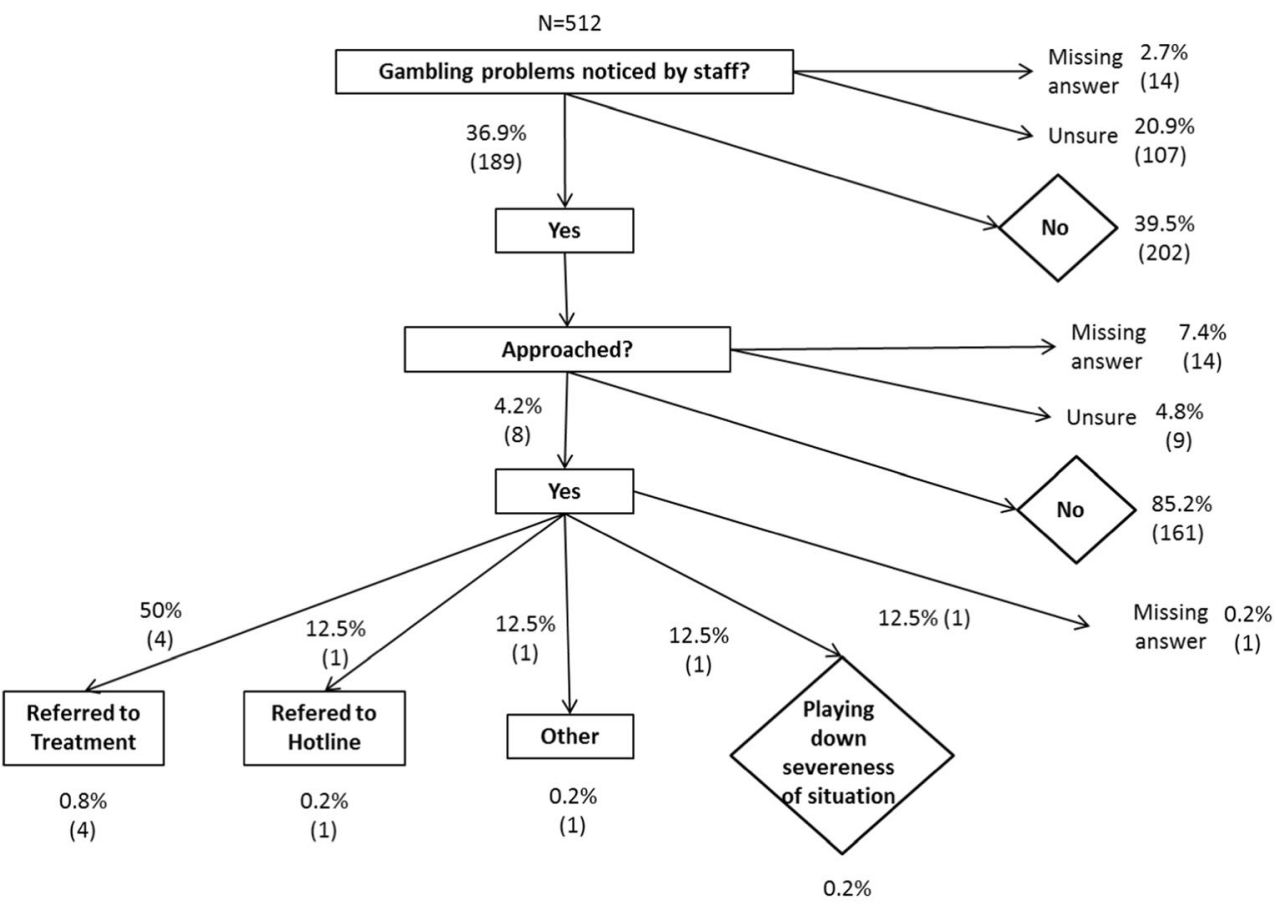

(1) machines during the last 12 months clearly showed noncompliance with this voluntary measure: only $1 \%$ of problem gamblers are actually approached with the intention to refer them to the help system. While we acknowledge the possibility that operators might simply lack expertise in the implementation of RG programs or had inadequate staff trainings, we deem it is more likely that the operators lack interest in effective $\mathrm{RG}$ efforts.

We argue that slot machine hall operators lack interest in effective CSR because of financial incentives. As shown in the literature review, evidence clearly suggests that a large portion of revenues from slot machines comes from problem gamblers and that problem gamblers are the best customers for slot machine operators. With the majority of revenue coming from exactly the group of customers that should be stopped from gambling, it is obvious that effective RG measures are in opposition to the financial interests of operators. In fact, there is a strong financial incentive for gambling operators not to voluntarily implement effective prevention measures as the operator would otherwise lose the revenue share from problem gamblers, who contribute more than half of their total revenue. In a competitive market like the German slot machine business, a different operator might choose not to implement such effective RG measures and benefit at the expense of those operators who act in compliance with public health. It could thus be financially too detrimental for an operator to implement effective voluntary RG measures. This explanation could be generalized to the hypothesis that corporate responsibility as a set of rules does not work when it is opposed to financial incentives.
With respect to RG, this logic implies that one of the most important tasks is to remove the conflict of interest between financial interests and helping problem gamblers. A solution could be to remove the responsibility for preventing problem gambling from the operators, instead giving full authority to an external decision maker, for example, the Ministry of Health. The operators then could adhere to mandatory rules set by the external decision maker.

\section{Limitations}

A few limitations need to be considered when interpreting the results. First, the sample of gamblers in treatment is not fully representative of all gamblers who should be approached according to RG programs. That is, staff should approach not only problem gamblers who are in treatment but also all problem gamblers as well as potential problem gamblers. It could be argued that gamblers in treatment might show (or have shown) more signs of problems than problem gamblers not in treatment or at least more than potential problem gamblers. They would then be easier to identify by staff. Therefore, the results for the approached gamblers could be an overestimation, and the share of all problem gamblers that are actually approached is even lower.

Second, we note that there is a level of discretion when it comes to the implementation of RG programs and staff training. For example, if an employee does not approach a potential problem gambler, the reason could be that they do not perceive the gambler's behavior as potentially problematic 
or that they perceived the behavior as problematic, but actively decided not to approach the gambler. Hence, approaching a gambler depends on a subjective component related to the staff as well as their willingness to approach gamblers. The particular reasons for not approaching a gambler could be multifold, e.g., pure laziness, being too busy, or being implicitly told not to approach customers and disturb their playing rhythm.

Finally, the results are based on a survey from 2014. The introduction of mandatory $R G$ programs only came into effect as of July 1, 2012. It is possible that the interviewed gamblers may have been responding to their experience before the introduction of these programs. In that case, the reported approaches are likely an underestimation. But this is rather unlikely, since only respondents who gambled in the past 12 months primarily in slot machine halls were selected in the study. It could further be the case that some gamblers played in slot machine halls that were operated by companies that were not part of the analysis and that do not require their staff to approach potential problem gamblers. However, this can only represent a very small group, since all major operators were included in our study.

\section{Conclusion}

We examined the clash between financial interests and corporate social responsibility in the gambling market using an example of seven German slot machines operators and their RG programs. We analyzed the programs qualitatively and observed that they mainly include measures that are mandatory by law but only one voluntary measure deemed an effective tool to prevent gambling addiction: approaching potential problem gamblers by staff with the intention to reduce their gambling exposure or refer them to the help system. Other voluntary measures such as (self-)limitation and (self-)exclusion systems or a reduction in playing speed were absent.

Furthermore, we analyzed the implementation of the voluntary measure of approaching potential problem gamblers by a survey of 705 gamblers in treatment. Of the 512 past-year gamblers who indicated doing so primarily in slot machine halls, only 29 were approached by staff members with the intention to discourage further gambling after significant losses had been noticed, while 97 gamblers were actually encouraged to continue gambling. In total, only five gamblers were approached with the intention to refer them to treatment after their gambling problems had been witnessed. We interpret this as a clear violation of the alleged goals of the RG programs. Together with the absence of other potentially effective voluntary measures in these programs, we conclude that the examined gambling operators do not surpass the level of player protection that is required and enforced by law. This finding would be even stronger if the measure to approach potential problem gamblers were not seen as voluntary but as mandatory. In that case operators would not only violate their own conduct but show an even lower level of player protection than demanded by law.

We argue that this finding can be explained by the opposing interests between player protection and the financial incentives of serving problem gamblers as a significant customer base with high spending that account for a large share of the total revenue of slot machine halls. This result suggests that corporate responsibility is ineffective when it is opposed to financial incentives. We thus argue that businesses are only acting voluntarily in the interest of public health if it either generates more profits (e.g., it is rewarded by the consumers) or at least is not harming profitability. Therefore, whenever public health is opposed to financial interests, enforced mandatory rules are the standard that can be expected in a competitive market, but nothing more. If a business upholds higher standards that harm its bottom line, its profits will decrease, and the business will lose out to competitors and eventually cease to exist. Therefore, corporate social responsibility works best when business interests are not at stake, while otherwise mandatory rules with enforcement are needed. Optimally, such mandatory rules will align financial interests with public health.

Acknowledgements Ingo Fiedler received funding from Hamburg's Ministry of the Interior to conduct this study (no grant number).

Funding Information Open Access funding provided by Projekt DEAL.

\section{Compliance with ethical standards}

Conflict of interest Ingo Fiedler, Sylvia Kairouz, and Jennifer Reynolds declare that they have no conflict of interest.

Ethical approval All procedures performed in studies involving human participants were in accordance with the ethical standards of the institutional and/or national research committee and with the 1964 Helsinki Declaration and its later amendments or comparable ethical standards.

Informed consent Informed consent was obtained from all individual participants included in the study.

Open Access This article is licensed under a Creative Commons Attribution 4.0 International License, which permits use, sharing, adaptation, distribution and reproduction in any medium or format, as long as you give appropriate credit to the original author(s) and the source, provide a link to the Creative Commons licence, and indicate if changes were made. The images or other third party material in this article are included in the article's Creative Commons licence, unless indicated otherwise in a credit line to the material. If material is not included in the article's Creative Commons licence and your intended use is not permitted by statutory regulation or exceeds the permitted use, you will need to obtain permission directly from the copyright holder. To view a copy of this licence, visit http://creativecommons.org/licenses/by/4.0/. 


\section{References}

Babor T, Robaina K (2013) Public health, academic medicine, and the alcohol Industry's corporate social responsibility activities. Am J Public Health 103(2):206-214

Barry AE, Goodson P (2010) Use (and misuse) of the responsible drinking message in public health and alcohol advertising: a review. Health Educ Behav 37(2):288-303

Blaszczynski A, Ladouceur R, Shaffer HJ (2004) A science-based framework for responsible gambling: the Reno model. J Gambl Stud 20(3):301-317. https://doi.org/10.1023/B:JOGS.0000040281. 49444.e2

Blaszczynski A, Ladouceur R, Nower L, Shaffer H (2008) Informed choice and gambling: principles for consumer protection. J Gambl Bus Econ 2(1):103-118

Blaszczynski A, Collins P, Fong D, Ladouceur R, Nower L, Shaffer HJ, Tavares H, Venisse JL (2011) Responsible gambling: general principles and minimal requirements. J Gambl Stud 27(4):565-573. https://doi.org/10.1007/s10899-010-9214-0

Brosowski T, Hayer T, Meyer G, Rumpf H-J, John U, Bischof A (2015) Thresholds of probable problematic gambling involvement for the German population: results of the pathological gambling and epidemiology (PAGE) study. Psychol Addict Behav 29:794-804

Cai Y, Jo H, Pan C (2012) Doing well while doing bad? CSR in controversial industry sectors. Journal of Business Ethics 108(4): 467-480. https://doi.org/10.1007/s10551-011-1103-7

Casswell S, Thamarangsi T (2009) Reducing harm from alcohol: call to action. Lancet 373(9682):2247-2257

Collins P, Blaszczynski A, Ladouceur R, Shaffer J, Fong D, Venisse J-L (2015) Responsible gambling: conceptual considerations. Gaming Law Rev Econ 19(8):594-599. https://doi.org/10.1089/glre.2015. 1985

Currie SR, Miller NV, Hodgins DC, Wang J (2009) Defining a threshold of harm from gambling for population health surveillance research. Int Gambl Stud 9:19-38

Devinney TM (2009) Is the socially responsible corporation a myth? The good, the bad, and the ugly of corporate social responsibility. Academy of Management Perspectives 23(2):44-56. https://doi. org/10.5465/AMP.2009.39985540

Dunstone K, Brennan E, Slater MD, Dixon HG, Durkin SJ, Pettigrew S, Wakefield MA (2017) Alcohol harm reduction advertisements: a content analysis of topic, objective, emotional tone, execution and target audience. BMC Public Health 17(1):1-13

Fiedler I (2012) The gambling habits of online poker players. J Gambl Bus Econ 6:1-23

Fiedler I (2016) Glücksspiele: Eine verhaltens- und gesundheitsökonomische Analyse mit rechtspolitischen Empfehlungen. Peter Lang Verlag, Frankfurt

Fiedler I, Kairouz S, Costes J-M, Weißmüller KS (2019) Gambling spending and its concentration on problem gamblers. J Bus Res 98:82-91

Garriga E, Melé D (2004) Corporate social responsibility theories: mapping the territory. J Bus Ethics 53(1-2):51-71

Hessari NM, Petticrew M (2017) What does the alcohol industry mean by "responsible drinking"? A comparative analysis. J Public Health 40(1):90-97
Hing N (2002) The emergence of problem gambling as a corporate social issue in Australia. Int Gambl Stud 2:101-122

Hing N (2010) The evolution of responsible gambling policy and practice: insights for Asia from Australia. Asian J Gambl Issues Public Health 1(1):19-33

Jones SC, Hall S, Kypri K (2017) Should I drink responsibly, safely or properly? Confusing messages about reducing alcohol-related harm. PLoS One 12(9):1-14

Korn D, Shaffer H (1999) Gambling and the health of the public: adopting a public health perspective. J Gambl Stud 15(4):290-364

Ladouceur R, Shaffer P, Blaszczynski A, Shaffer HJ (2017) Responsible gambling: a synthesis of the empirical evidence. Addict Res Theory 25(3):225-235. https://doi.org/10.1080/16066359.2016.1245294

Leung TCH, Snell RS (2017) Attraction or distraction? Corporate social responsibility in Macao's gambling industry. J Bus Ethics 145: $637-658$

Mayfield D, McLeod G, Hall P (1974) The CAGE questionnaire: validation of a new alcoholism screening instrument. The American Journal of Psychiatry 131(10):1121-1123

Petry J (2003) Glücksspielsucht. Hogrefe, Göttingen

Pettigrew S, Biagioni N, Daube M, Stafford J, Jones SC, Chikritzhs T (2016) Reverse engineering a 'responsible drinking' campaign to assess strategic intent. Addiction 111(6):1107-1113

Productivity Commission (2010) Gambling. Productivity Commission, Canberra

Reith G (2008) Reflections on responsibility. J Gambl Issues 22:149-155

Room R, Babor T, Rehm J (2005) Alcohol and public health. Lancet 365(9458):519-230

Savell E, Fooks G, Gilmore AB (2016) How does the alcohol industry attempt to influence marketing regulations? A systematic review. Addiction 111(1):18-32

Smith GJ, Wynne HJ (2002) Measuring gambling and problem gambling in Alberta using the Canadian problem gambling index (CPGI): final report. Alberta Gabling Research Institute, Calgary

Swathi R (2018) A study on role of corporate social responsibility in organizations. Glob J Res Anal 7(2):342-346

The Commission of the European Communities (2001) Green paper: promoting a European framework for corporate social responsibility. EU Commission, Brussels

Tom MA, LaPlante DA, Shaffer HJ (2014) Does Pareto rule internet gambling? Problems among the "vital few" \& "trivial many". J Gambl Bus Econ 8(1):73-100

Volberg RA, Bernhard B (2006) The 2006 study of gambling and problem gambling in New Mexico: report to the responsible gaming Association of new Mexico. Gemini Research, Northampton

Wiebe J, Mun P, Kauffman N (2006) Gambling and problem gambling in Ontario 2005. Council, Responsible Gaming

Williams RJ, Wood RT (2007) The proportion of Ontario gambling revenue derived from problem gamblers. Can Public Policy 33: $367-387$

Publisher's note Springer Nature remains neutral with regard to jurisdictional claims in published maps and institutional affiliations. 